\title{
Factors Influencing Teachers' Continuation of Online Learning in Elementary Schools
}

\author{
Abdullah Masmali ${ }^{1,3}$ \& Fahhad Alghamdi ${ }^{2}$ \\ ${ }^{1}$ Ministry of Education, Jazan Region, Saudi Arabia \\ ${ }^{2}$ Ministry of Education, Al-Baha Region, Saudi Arabia \\ ${ }^{3}$ Kansas State University, Manhattan, KS, USA \\ Correspondence: Abdullah Masmali, Ministry of Education, Jazan Region, Saudi Arabia; Kansas State University, \\ Manhattan, KS, USA.
}

Received: July 30, 2021

Accepted: October 16, $2021 \quad$ Online Published: November 22, 2021

doi:10.5539/ies.v14n12p31

URL: https://doi.org/10.5539/ies.v14n12p31

\begin{abstract}
The use of online teaching has increased rapidly, especially since the start of the global pandemic of COVID-19. $\mathrm{K}-12$ teachers in Saudi Arabia, like many teachers globally, found themselves with a new way of teaching because of the pandemic. Thus, this study examined the unified theory of acceptance and use of technology (UTAUT) in elementary school teachers' acceptance of online learning. We tested whether UTAUT's four key factors (performance expectancy; effort expectancy; social influence; and facilitating conditions) affect Saudi Arabian elementary school teachers' acceptance of using online learning. We found that performance expectancy, social influence, and facilitating conditions altogether predicted teachers' use of online learning as the analysis of the multiple regression outcome found that $60.2 \%$ of the variation was affected by these variables.
\end{abstract}

Keywords: online learning, unified theory of acceptance and use of technology, UTAUT, technology acceptance, elementary school, teacher

\section{Introduction}

Early in 2020, most countries declared the COVID-19 pandemic a national emergency. As a result, many countries have taken strict measures to limit the spread of this virus. The Saudi Arabian government was one of the first to take multiple measures to deal with this crisis, such as locking down cities, banning travel, closing educational institutions, and enforcing social distancing. In this situation, schools were unable to host students and conduct learning and other activities normally.

This crisis made the Ministry of Education insist on online learning in all schools and universities around the country. However, many teachers and students, especially in elementary schools, were unfamiliar with online learning. This method of learning was challenging for educators and students alike as it was implemented as an emergency solution for a specific situation, which many educators and students were unprepared for. As a result, the Ministry of Education launched the Madrasati platform, and teachers used different resources in the platform to support teaching and give students a proper education despite the challenges of online teaching.

Prior to the COVID-19 pandemic, the Ministry of Education in Saudi Arabia had made extensive efforts to transform the education system to digital learning. One of these efforts was the push to transform education into digital learning by 2020 (Alsaleh, 2019). This initiative targeted middle and secondary schools in three phases by establishing a learning management system called Future Gate (Alsaleh, 2019). This was one of the main factors that helped the Ministry of Education to quickly switch to remote learning at the beginning of the pandemic in March 2020. However, it was easier for the Ministry to include elementary schools in a unified platform at the beginning of the pandemic.

The Ministry of Education (2021) released a statistical report regarding the use of the Madrasati platform from the beginning of the transition to online learning because of the COVID-19 pandemic. The report explained that for the total number of public schools that used the Madrasati platform, there were 4,982,474 students, 408,816 teachers, 18,021 school leaders, 8,077 educational supervisors, and 923,784 parents participated in the platform. The total number of visits to Madrasati links was 588,000,000. The number of virtual lessons created was $120,035,981$. The number of virtual lessons created daily was $1,000,000+$. The number of assignments given was 
$35,975,279$. The number of satellite channels was 23 . The total number of satellite hours was 186,000 . The total number of satellite broadcasts was 31,500. All these large numbers indicate the dedicated effort from the Ministry of Education to deal with the situation and make the learning process continue without affecting students' learning.

Transformation to digital learning by 2020 started with the Ministry of Education in Saudi Arabia launching some initiatives such as the Virtual School project (Oraif \& Elyas, 2021) and the Future Gate learning management system (Alsaleh, 2019). Therefore, teachers' acceptance of using online learning is part of shifting to digitalizing learning to improve and develop learning that will help students to achieve further knowledge and skills in using technology to facilitate their access to information.

\subsection{The Benefits of Online Learning}

It is crucial to outline the primary benefits of online learning in improving learning. Online learning was quickly accepted in the education domain because it provided various benefits to the stakeholders in the learning environment, particularly teachers and students. These benefits include fast access to information, better delivery of content interactivity, convenience, and continuous distribution of subjects (Liu et al., 2020).

One of the essential primary advantages of online learning is the flexible delivery of learning processes (Appana, 2008). Therefore, challenges with time and distance become eliminated, which makes the learning process universal regardless of geographical location. Zamfir (2020) argued that online learning's flexibility and its capacity to enhance teaching using virtual classrooms and distance learning models make it well suited to better learning processes. Moreover, online learning assists in transforming learning from the use of internet sources to an engaged, active, self-directed, and interactive model that helps learners enhance their knowledge and promotes their understanding of the skills needed (Zamfir, 2020).

Furthermore, enabling communication and interaction through online learning can enhance the cycles of conventional transmission among teachers and students by creating a new environment. This new environment can be elastic in providing many opportunities that foster learning activities for enhancing learners' information retention compared to offline education (Velichova et al., 2020). Furthermore, according to assorted empirical evidence by Al Hashlamoun and Daouk (2020), online learning assists in exchanging thoughts, discussions, reflections, and ideas; negotiating; giving feedback; and working together in group projects. As a result, online learning is a channel that motivates students to participate and engage in learning activities to expand their knowledge.

\subsection{Acceptance Model}

One of the common models used in the information and communication technology (ICT) field is UTAUT (Venkatesh et al., 2003). The UTAUT model and its four key factors (i.e., performance expectancy, effort expectancy, social influence, and facilitating conditions) are still the foundation for many studies on technology acceptance (Garone et al., 2019). Studies have confirmed that UTAUT is robust and effective, but there is a lack of studies that examine its effects in relation to age, gender, experience, and voluntariness (Venkatesh et al., 2003). This study's model focuses on users' intentions to use technology.

The first UTAUT factor is performance expectancy (PE), in which a person believes that using technology will enhance task performance (Venkatesh et al., 2003). Teachers' confidence in this factor is assessed through the effective use of online learning, especially in regard to consistency of use and daily routines. The second factor is effort expectancy (EE), which refers to the level of convenience that affects a person when using technology (Venkatesh et al., 2003). Teachers' skills in using online learning are vital to ensure that they use the platform and online learning effectively. Social influence (SI) is the third factor by which an individual is viewed as important and believed by others to use technology (Venkatesh et al., 2003). Teachers' use of online learning could be activated by the influence of other teachers, administrators, a community, and even students. According to Venkatesh et al., when a new system or technology is mandated rather than deployed on a voluntary basis, social influence becomes a significant predictor. The fourth factor is facilitating conditions (FC), when teachers believe that providing infrastructure and technology support will help to use technology effectively (Venkatesh et al., 2003). In online learning, computer devices and the internet play significant roles in encouraging teachers to use online learning platforms effectively.

\subsection{Studies Related to Online Learning}

To fulfill the goals and obtain the usefulness of online learning efforts, it is essential to analyze the factors determining teachers' acceptance of online learning to improve the quality of education. In line with this, Tandon (2020) employed UTAUT to examine the factors influencing the use and adoption of online learning, especially during pandemic outbreaks. The study displayed performance expectancy, social effects, and facilitating factors 
that positively impacted the learners' behaviors. Furthermore, Tandon found that attitude impacted behavioral intention and actual use significantly. Nonetheless, effort expectancy was unsuccessful for transitioning teachers' choices toward online teaching. In contrast, some studies have reported the effects of effort expectancy (Bellaaj et al., 2015; Khatibi \& Azam, 2019). Bellaaj et al. (2015), for example, discovered that expectations concerning performance positively influenced the acceptance of e-learning. With the availability of internet learning, expectancy performance levels have gone up drastically, while the element of effort expectancy has decreased.

While various studies have emphasized the importance of social influence and its positive impact on behavioral intention (Cao et al., 2021; Radovan \& Kristl, 2017), others have stated that social influence does not have a significant effect. For instance, Gunasinghe et al. (2019) examined UTAUT's sufficiency in explaining academics' acceptance of e-learning. Individual innovativeness in IT and social influence were not crucial factors in relation to e-learning, whereas effort expectancy, performance expectancy, facilitating conditions, hedonic motivation, and habit motivation were essential elements in academics' adoption of e-learning.

Almaiah et al. (2020) argued that successful online learning system deployment depends on comprehending the adoption parameters that affect the current e-learning process. Therefore, these scholars investigated the significant aspects that affect electronic studying and online services in the COVID-19 pandemic period. They found critical features impacting online learning use (i.e., cultural aspects, technological factors, and self-efficacy factors). If education institutions address these in the future, they may have substantial improvements in learning outcomes.

\section{Research Problem}

The transformation to online learning because of the COVID-19 pandemic has definitely had an impact on teachers' attitudes toward this method of teaching. In Saudi Arabia, it was easier for higher education instructors to move to online learning with their experience of using a learning management system in higher education. In middle and secondary public schools, many teachers had started using a learning management system 2 years before the pandemic, as the Department of Education had started training teachers to use a learning management system in teaching. However, elementary school teachers were not ready to transform to digital learning and use a learning management system for teaching elementary school students. When the COVID-19 pandemic appeared, the use of online learning in elementary schools became compulsory. The Ministry of Education used an online platform called Madrasati, which was available for teachers to use as an alternative option for teaching. Previous studies have examined online learning acceptance in higher education and in secondary schools in depth (Alahmari \& Amirault, 2017; Holmes \& Prieto-Rodriguez, 2018; Klobas \& McGill, 2010; Rucker \& Downey, 2016). Therefore, it is essential to conduct studies to ascertain how UTAUT could help understand the willingness of elementary school teachers to accept, adopt, and continue using online learning. In this study, we used the UTAUT model first proposed by Venkatesh et al. (2003).

\section{The Study Question}

We designed this study to answer the following research question: Are the independent variables of performance expectancy, effort expectancy, social influence, and facilitating conditions significant predictors of elementary school teachers' behavioral intention to continue using online learning significant?

\section{Method}

\subsection{Population and Sampling}

The population of this study was teachers from a public elementary school in the General Educational Administration of the Al Bahah Region, Saudi Arabia. Online learning through learning management systems is not new to some schools in the region, particularly in some middle and secondary schools that had started the transformation to digital learning through Future Gate LMS. The data collection used convenience sampling to select a sample from the population, which were elementary school teachers from the Department of Education in Albaha Region. There were about 3,748 elementary school teachers in the Albaha Region at the time of data collection (Open Data, 2021) in the spring semester of 2021. The online survey was distributed through a link to 242 elementary school teachers in four social media groups specifically for teachers in this region; 119 participants returned the survey, with a response rate of $47 \%$. There were five incomplete answers from participants; therefore, we used valid responses from 114 participants in the analysis process.

\subsection{Instrument}

We used an instrument adapted from the UTAUT questionnaire (Venkatesh et al., 2003). The survey was initially developed in the English language, and the final version was translated into the Arabic language because it was the participants' first language. To ensure the validity of the Arabic version, a third party reviewed the survey. The 
final version of the questionnaire was created after a few small wording variations in the two languages were corrected. This instrument is frequently validated and commonly used (Alawadhi \& Morris, 2008). A number of studies have reported the reliability of the measurement scales of UTAUT. For example, Omar et al. (2019) four the Cronbach's alpha of all UTAUT was $>0.9$, which indicates the reliability of the scales of measurement. In this study, the instrument consists of two sections. One measures teachers' demographic information, and the other section measures the UTAUT constructions, which are performance experience (PE), effort expectancy (EE), social influence (SI), facilitating conditions (FC), and behavioral intention (BI). A 5-point Likert scale was used for measuring the instrument's items, ranging from 1 ("strongly disagree") to 5 ("strongly agree").

\subsection{Measurement Validity and Reliability}

The validity of this study instrument was established by measuring the content validity. Content validity was defined by Bollen (1989) as "a qualitative type of validity where the domain of the concept is made clear and the analyst judges whether the measures fully represent the domain" (p. 185). A group of experts who speak both Arabic and English gave their feedback regarding the measuring of the UTAUT items constructs. They provided their feedback, and after reviewing their recommendations, the researchers made a few changes to the survey's wording to meet the highest level of validity for the survey's contents. The researchers established the reliability of the instrument by calculating Cronbach's alpha to determine the internal consistency of each UTAUT scale. When the items in a scale have a Cronbach's alpha closer to 1.0, this represents a greater level of internal consistency (Gliem \& Gliem, 2003). In this study, the results of Cronbach's alpha of UTAUT scales ranged from .72-.95, indicating excellent reliability of each scale according to George and Mallery (2003), as depicted in Table 1.

Table 1. Cronbach's Alpha inter

\begin{tabular}{ccc}
\hline Construct & Number of Item & Cronbach's Alpha \\
\hline EP & 4 & .89 \\
EE & 4 & .91 \\
SI & 4 & .72 \\
FC & 4 & .84 \\
BI & 3 & .95 \\
\hline
\end{tabular}

\subsection{The Regression}

We conducted multiple regression analyses to determine the effect of performance expectancy, effort expectancy, social influence, and facilitating conditions on elementary school teachers' behavioral intention to continue using online learning in Saudi Arabia. The basic assumptions of the regression analysis, such as normality, multicollinearity, and linearity, were tested prior to performing the regression analysis. The data were normally distributed, and the assumption of absence of multicollinearity was met.

\section{Results}

Include in the Method section information that provides definitions of all primary and secondary outcome measures and covariates, including measures collected but not included in this report. Describe the methods used to collect data (e.g., written questionnaires, interviews, observations) as well as methods used to enhance the quality of the measurements (e.g., the training and reliability of assessors or the use of multiple observations). Provide information on instruments used, including their psychometric and biometric properties and evidence of cultural validity.

\subsection{Participant Profile}

As shown in Table 2, the results of descriptive statistics indicated that of the 114 participants who took the survey, $40.4 \%$ were male, and $59.6 \%$ were female. The majority of teachers who participated in this study were 38 years old or above $(67.5 \%)$, followed by the group aged $32-37$ years $(25.4 \%)$. The majority of participants in this study (46.5\%) reported that they had 16 years or more teaching experience, followed by participants with 6-10 years of teaching experience $(25.4 \%)$, followed by participants with $11-15$ years of teaching experience $(17.5 \%)$. In terms of teachers' level of experience in using computer applications and the internet, most participants self-evaluated that they had average experience $(60.5 \%)$, while $28.1 \%$ were experts, and only $11.4 \%$ were beginners in using computer applications and the internet, as depicted in Table 2. 
Table 2. Participant characteristics

\begin{tabular}{lccc}
\hline Measure & Item & Total Number $(\mathrm{N}=114)$ & Percentage \\
\hline \multirow{2}{*}{ Gender } & Male & 46 & $40.4 \%$ \\
& Female & 68 & $59.6 \%$ \\
\hline \multirow{2}{*}{ Age } & 26 or less & 2 & $1.8 \%$ \\
& $27-31$ & 6 & $5.3 \%$ \\
& $32-37$ & 29 & $25.4 \%$ \\
Years of teaching experience & 38 or more & 77 & $67.5 \%$ \\
\hline & 5 years or less & 12 & $10.5 \%$ \\
& $6-10$ & 29 & $25.4 \%$ \\
Experience with using computer applications and Internet & $11-15$ & 20 & $17.5 \%$ \\
& 16 or more & 53 & $46.5 \%$ \\
\hline
\end{tabular}

\subsection{Means, Standard Deviations, and Normality Test}

Field (2009) stated that data can be regarded as normally distributed if the result of skewness and kurtosis lies between \pm 2.00 at $p<-0.01$. The test results of skewness and kurtosis on UTAUT fall within the acceptable range. Therefore, we concluded that the data were normally distributed.

Table 3. Means, standard deviations, and normality test

\begin{tabular}{cccc}
\hline Construct & Skewness & Kurtosis & Mean \\
\hline PE & .826 & .102 & 3.60 \\
EE & 1.027 & 1.703 & 3.67 \\
SI & .544 & .798 & 3.12 \\
FC & .882 & 1.038 & 2.95 \\
BI & .882 & .669 & 3.45 \\
\hline
\end{tabular}

\subsection{Multicollinearity Test}

According to Field (2009), a regression model shows no multicollinearity if the tolerance value is greater than 0.1 and the VIF value is less than 10. The test results shown in Table 4 indicate that there was no multicollinearity because all tolerance values exceeded the 0.1 constraint, and the VIF values were less than 10 for all UTAUT constructs.

Table 4. Multicollinearity test

\begin{tabular}{ccc}
\hline Construct & Tolerance & VIF \\
\hline EE & .268 & 3.730 \\
SI & .554 & 1.805 \\
FC & .322 & 3.105 \\
PE & .399 & 2.509 \\
\hline
\end{tabular}

The residual plots were constructed to check for outliers and linearity that indicate the relationship between independent and dependent variables. The results of the standardized residual plots showed no outliers. The results also showed a linear relationship between the variables, and there was no heteroscedasticity. The results in Table 5 below show that all variables were positively related to each other. For example, social influence (SI) was positively related to performance experience $(\mathrm{PE})(\mathrm{r}=0.588, \mathrm{p}=0.01)$. 
Table 5. UTAUT constructs correlations

\begin{tabular}{cccccc}
\hline Variable & PE & EE & SI & FC & BI \\
\hline PE & 1 & & & & \\
EE & $.725^{* *}$ & 1 & & & \\
SI & $.588^{* *}$ & $.633^{* *}$ & 1 & & \\
FC & $.696^{* *}$ & $.806^{* *}$ & $.607^{* *}$ & 1 & \\
PE & $.719^{* *}$ & $.622^{* *}$ & $.616^{* *}$ & $.665^{* *}$ & 1 \\
\hline
\end{tabular}

Table 6 shows the multiple regression model with all four predictors produced $\mathrm{R}^{2}=.602$, and $\mathrm{F}(4,109)=41.19, \mathrm{p}$ $<.001$. There was an independence of residuals, as assessed by a Durbin-Watson statistic of 2.19. Facilitating conditions, social influence, performance expectancy, and effort expectancy accounted for $60.2 \%$ of the variation in behavioral intention, with adjusted $\mathrm{R} 2=58.7 \%$, a medium to large size effect according to Cohen (1988).

In Table 7 , the results indicate that performance expectancy $(\beta=.458, p=.000)$ was a stronger predictor of Saudi teachers' behavioral intention to continue using online learning, indicating that participants who believed that the use of online learning would result in performance gains and who perceived online learning as useful were more likely to continue using online learning. Also, social influence $(\beta=239, \mathrm{p}=.000)$ and facilitating conditions $(\beta$ $=.285, \mathrm{p}=.000)$ were significant predictors. However, effort expectancy is not a significant predictor of elementary teachers' behavioral intention to use online learning.

Table 6. Regression: Model summary ${ }^{\mathrm{b}}$

\begin{tabular}{ccccc}
\hline Mode & $\mathrm{R}$ & R Square & $\begin{array}{c}\text { Adjusted R Aquare } \\
\text { Dubrin Watson }\end{array}$ & The Estimate \\
\hline 1 & $.766^{\mathrm{a}}$ & .602 & .587 & .59925 \\
& & & 2.188 & \\
\hline
\end{tabular}

Note. a. Predictor: (constant), facilitating conditions, social influence, performance expectancy, effect expectancy; b. Dependent variable: behavioral intention

Table 7. Coefficients ${ }^{\mathrm{a}}$

\begin{tabular}{|c|c|c|c|c|c|c|c|c|}
\hline \multirow[t]{2}{*}{ Model } & & \multicolumn{2}{|c|}{$\begin{array}{c}\text { Unstandardized } \\
\text { Coefficients }\end{array}$} & \multirow{2}{*}{$\begin{array}{c}\begin{array}{r}\text { Standardized } \\
\text { Coefficients }\end{array} \\
\text { Beta } \\
\end{array}$} & \multirow[t]{2}{*}{$\mathrm{t}$} & \multirow[t]{2}{*}{ Sig. } & \multicolumn{2}{|c|}{$95.0 \%$ Confidence Interval for B } \\
\hline & & $\mathrm{B}$ & Std. Error & & & & Upper Bound & Lower Bound \\
\hline \multirow[t]{5}{*}{1} & (Constant) & -.136 & .189 & & -.716 & .475 & .475 & .240 \\
\hline & Performance Expectancy & .525 & .110 & .458 & 4.781 & .000 & .000 & .743 \\
\hline & Effort Expectancy & -.143 & -.143 & -.103 & -.879 & .382 & .382 & .179 \\
\hline & Social Influence & .320 & .320 & .239 & 2.940 & .004 & .104 & .536 \\
\hline & Facilitating Conditions & .388 & .388 & .285 & 2.673 & .009 & .100 & .676 \\
\hline
\end{tabular}

Predictor: (constant), facilitating conditions, social influence, performance expectancy.

\section{Discussion}

In this study, we employed the UTAUT model to determine the factors that influence elementary school teachers' behavioral intention to use online learning in Saudi Arabia. The UTAUT model has constructs including performance expectancy, effort expectancy, social influence, and facilitating conditions; these constructs were used in this study as predictors for elementary school teachers' behavioral influence to use online learning. When three of the four constructs of the UTAUT model are significantly related to the teachers' behavioral intention, it signifies that teacher believe in the importance and usefulness of online learning through a learning management system. The findings show that performance expectancy, social influence, and facilitating conditions were significant factors that determined elementary school teachers' behavioral intention to use online learning. However, effort expectancy had an insignificant effect on teachers' behavior toward the continuing use of online teaching. In fact, regardless of effort expectancy, online learning is perceived as a useful technology for teachers to use.

The findings demonstrated that performance expectancy had a significant effect on teachers' behavioral intentions. 
Sangeeta et al. (2020), Bellaaj et al. (2015), and Gunasinghe et al. (2019) found that performance expectancy had a positive impact on behavioral intention. Our findings indicate the importance of implementing online learning for teaching elementary school students. This confirms the importance of designing useful instruction that helps to implement effective online learning based on expected performance that will affect teachers' behavioral intention to use or to continue using online learning. Omar (2019) found that performance expectancy has no positive impact on elementary school teachers to continue using online learning because teachers found it a challenge to adopt the skills and increase their motivations in using technology. Because the meaning of performance expectancy is that teachers believe using technology and online learning will enhance their job (Venkatesh et al., 2003), teachers in our study were required to use online learning to make them more confident to continue using online learning.

Effort expectancy in which the degree of ease is associated with the use of e-learning was not a significant predictor of elementary school teachers' behavioral intention to continue using online learning. The findings are consistent with those of Sangeeta et al. (2020), who found effort expectancy has no significant relationship with teachers' intention to continue using e-learning. However, this finding contradicted other studies that found effort expectancy to be a significant predictor of behavioral intention to use innovation (Bellaaj et al., 2015; Gunasinghe et al., 2019). Our findings also contradicted the original study by Venkatesh et al. (2003), the developer of UTAUT, because we found that the ease of using ICT was not related to teachers' behavioral intention to continue using e-learning. The ease of the Madrasati platform allowed teachers to adopt online learning quickly to help students learn in the pandemic period. The results suggest that elementary school teachers do not seem concerned about using or continuing to use e-learning. This implies that teachers are willing to use e-learning if they feel it will contribute to their improved teaching and thus make the effort to use it worthwhile.

The findings also revealed that facilitating conditions have a significant positive impact on teachers' behavioral intention to continue the use of e-learning. This finding is consistent with Sangeeta et al. (2020) and Gunasinghe et al. (2019), who held that facilitating conditions have a positive relationship with teachers' intention to continue using online learning. This is an important finding that indicates that technologies such as the Madrasati platform are effective and helpful for teachers and will help in their future use of online learning.

In this study, social influence was also a significant factor in teachers' behavioral intention to continue using online learning. Our findings are also consistent with a previous study by Sangeeta et al. (2020). This means that, in general, teachers used e-learning because of others' influence to use online learning. However, Sangeeta et al. (2020), Bellaaj et al. (2015) and Gunasinghe et al. (2019) found that social influence has no positive impact on teachers' behavioral intention to continue using online learning. Online learning through the Madrasati platform was mandated because of the COVID-19 pandemic, so social influence was a significant predictor of teachers' intention to continue using online learning. Venkatesh et al. (2003) explained that when a new system or technology is mandated rather than deployed on a voluntary basis, social influence becomes a significant predictor. However, the specific need to use online learning because of the pandemic affects teachers' influence by others to use online learning because this is the only way to continue school after the suspension of in-school teaching. This also might influence teachers to continue using online learning to support teaching after they are back at school.

\section{Conclusion}

In this study, we used the UTAUT model to explain the determinants for teachers to continue using online learning after they had to use it because of the COVID-19 pandemic. The findings reveal that teachers' acceptance to continue online learning is influenced by three factors: performance expectancy, social influence, and facilitating conditions.

The Ministry of Education in Saudi Arabia has made dedicated efforts to mitigate the damage to the educational process as the result of suspending school because of the COVID-19 pandemic. This was a chance for teachers to adopt online learning for future use after returning to school. Because online learning is new to most teachers, students, leaders, and parents, some work still needs to be done, and, of course, online learning will never reach perfection, especially because the transition was unplanned. But this might change many teachers' acceptance of online learning used in blended learning after returning to schools

\section{Limitations and Recommendation for Future Research}

While this study contributed to our knowledge about the factors that have affected teachers' acceptance of the use of online learning, there are some limitations to be considered in future research. The study did not examine the effects of some moderators on teachers' intentions to continue using online learning. Future research may examine the effect of other moderators, such as the teachers' gender and level of experience in using computers in education. The study was in only a quantitative design; future research might employ quantitative and qualitative methods such as applying interviews to some participants to get a better insight and confirming the quantitative 
results. Interviewing some teachers could be added to the study to gauge their thoughts and reflections about their intentions to continue using online learning.

\section{References}

Al Awadhi, S., \& Morris, A. (2008). The use of the UTAUT model in the adoption of e-government services in Kuwait. Proceedings of the 4lst Hawaii International Conference on System Sciences, 11-16. https://doi.org/10.1109/HICSS.2008.452

Al Hashlamoun, N., \& Daouk, L. (2020). Information technology teachers' perceptions of the benefits and efficacy of using online communities of practice when teaching computer skills classes. Education and Information Technologies, 25(6), 5753-5770. https://doi.org/10.1007/s10639-020-10242-z

Almaiah, M., Al-Khasawneh, A., Althunibat, A., \& Khawatreh, S. (2020). Mobile government adoption model based on combining GAM and UTAUT to explain factors according to adoption of mobile government services. International Journal of Interactive Mobile Technologies (iJIM), 14(3), 199-225. https://doi.org/10.3991/ijim.v14i03.11264

Alsaleh, B. A. (2019). K-12 Education reforms in Saudi Arabia: Implications for change management and leadership education. Teaching Educational Leadership in Muslim Countries (pp. 171-186). Springer. https://doi.org/10.1007/978-981-13-6818-9_10

Appana, S. (2008). A review of benefits and limitations of online learning in the context of the student, the instructor and the tenured faculty. International Journal on E-learning, 7(1), 5-22.

Bellaaj, M., Zekri, I., \& Albugami, M. (2015). The continued use of e-learning system: An empirical investigation using UTAUT model at the University of Tabuk. Journal of Theoretical \& Applied Information Technology, 72(3), 464-474.

Cao, J., Yang, T., Lai, I. K. W., \& Wu, J. (2021). Is online education more welcomed during COVID-19? An empirical study of social impact theory on online tutoring platforms. The International Journal of Electrical Engineering \& Education. https://doi.org/10.1177/0020720920984001

Field, A. (2009). Discovering statistics using SPSS. (3rd ed.). Sage.

Garone, A., Pynoo, B., Tondeur, J., Cocquyt, C., Vanslambrouck, S., Bruggeman, B., \& Struyven, K. (2019). Clustering university teaching staff through UTAUT: Implications for the acceptance of a new learning management system. British Journal of Educational Technology, 50(5), 2466-2483. https://doi.org/10.1111/bjet.12867

Gunasinghe, A., Abd Hamid, J., Khatibi, A., \& Azam, S. F. (2019). Academicians' acceptance of online learning environments: A review of information system theories and models. Global Journal of Computer Science and Technology, 19(1-H), 30-39. https://doi.org/10.34257/GJCSTHVOL19IS1PG31

Holmes, K. A., \& Prieto-Rodriguez, E. (2018). Student and staff perceptions of a learning management system for blended learning in teacher education. Australian Journal of Teacher Education, 43(3), 21-34. https://doi.org/10.14221/ajte.2018v43n3.2

Klobas, J. E., \& McGill, T. J. (2010). The role of involvement in learning management system success. Journal of Computing in Higher Education, 22(2), 114-134. https://doi.org/10.1007/s12528-010-9032-5

Liu, Z. Y., Lomovtseva, N., \& Korobeynikova, E. (2020). Online learning platforms: Reconstructing modern higher education. International Journal of Emerging Technologies in Learning (iJET), 15(13), 4-21. https://doi.org/10.3991/ijet.v15i13.14645

Minister of Education [minister_moe_sa]. (2021, March 8). Statistics of the Ministry of Education during a year of distance education [Tweet]. Twitter. Retrieved from https://twitter.com/tc_mohe/status/1369024821036716034?s=10

Omar, M., \& Ismail, S. (2019). The Influence of Mobile Technology Adoption among Secondary School Teachers Using the UTAUT2 Model. International Journal of Recent Technology and Engineering, 8(4), 3827-3831. https://doi.org/10.35940/ijrte.d8204.118419

Oraif, I., \& Elyas, T. (2021). The impact of COVID-19 on learning: Investigating EFL learners' engagement in online courses in Saudi Arabia. Education Sciences, 11(3), 1-19. https://doi.org/10.3390/educsci11030099

Radovan, M., \& Kristl, N. (2017). Acceptance of technology and its impact on teachers' activities in virtual classroom: Integrating UTAUT and CoI into a combined model. Turkish Online Journal of Educational 
Technology-TOJET, 16(3), 11-22.

Rucker, R., \& Downey, S. (2016). Faculty technology usage resulting from institutional migration to a new learning management system. Online Journal of Distance Learning Administration, 19(1). Retrieved from https://eric.ed.gov/?id=EJ1093948

Sangeeta, \& Tandon, U. (2020). Factors influencing adoption of online teaching by school teachers: A study during COVID-19 pandemic. Journal of Public Affairs, 1-11. https://doi.org/10.1002/pa.2503

Tandon, U. (2020). Factors influencing adoption of online teaching by school teachers: A study during COVID-19 pandemic. Journal of Public Affairs, e2503. https://doi.org/10.1002/pa.2503

Velichová, L., Orbánová, D., \& Kúbeková, A. (2020). The COVID-19 pandemic: Unique opportunity to develop online learning. TEM Journal, 9(4), 1633-1638. https://doi.org/10.18421/tem94-40

Venkatesh, V., Morris, M. G., Davis, G. B., \& Davis, F. D. (2003). User acceptance of information technology: Toward a unified view. MIS Quarterly, 27(3), 425-478. https://doi.org/10.2307/30036540

Zamfir, P. B. (2020). Online learning-Paradigm shift in the educational space. Analele Universitatii, "Constantin Brancusi" din Targu Jiu-Seria Litere si Stiinte Sociale, 2, 7-12.

\section{Copyrights}

Copyright for this article is retained by the author(s), with first publication rights granted to the journal.

This is an open-access article distributed under the terms and conditions of the Creative Commons Attribution license (http://creativecommons.org/licenses/by/4.0/). 